\title{
Hearing their Voices: Factors Doctoral Candidates Attribute to their Persistence
}

\author{
Lucinda S. Spaulding and Amanda J. Rockinson-Szapkiw \\ Liberty University, Lynchburg, VA, USA
}

\author{
Isspaulding@liberty.edu; aszapkiw@liberty.edu
}

\begin{abstract}
The purpose of this phenomenological inquiry was to examine persistence factors associated with the successful completion of a doctoral degree in the field of education. Standardized open-ended interviews with a purposeful sample of 76 participants (42 females, 34 males) generated data leading to themes describing what doctoral students experience (personal sacrifice, delayed expectations, dissertation challenges) and the personal factors (motivations for pursuing the degree, reasons for persisting, strategies for dissertation completion), social factors (support systems and coping mechanisms), and institutional factors (program characteristics) participants associated with their persistence. These findings provide a composite understanding of the essence of the struggles inherent in the journey and the factors associated with doctoral persistence. Implications and recommendations for doctoral candidates are discussed.
\end{abstract}

Keywords: persistence, doctorate, dissertation, attrition, phenomenology, teacher education

\section{Introduction}

Doctoral persistence is "the continuance of a student's progress toward the completion of a doctoral degree” (Bair, 1999, p. 8). Studies over the last four decades show that $40 \%$ to $60 \%$ of doctoral candidates at some stage in the process fail to demonstrate doctoral persistence; that is, they do not achieve their goal of earning a terminal degree (Berelson, 1960; Bowen \& Rudenstine, 1992; Council of Graduate Schools Ph.D. Completion Project, 2008). This phenomenon of doctoral persistence and its converse, attrition, is most puzzling given that "Paradoxically, the most academically capable, most academically successful, most stringently evaluated, and most carefully selected students in the entire higher education system — doctoral students-are the least likely to complete their chosen academic goals” (Golde, 2000, p. 199).

In education graduate programs, the attrition rate is estimated to be 50\% (Ivankova \& Stick, 2007), and some reports indicate it may be as high as 70\% (Nettles \& Millet, 2006). Between 1983 and 2008 time-to-degree completion for graduate students in education programs increased from 11.7 years to 12.7 years, while decreasing from 8.2 years to 7.7 years in all other fields (Na-

Material published as part of this publication, either on-line or in print, is copyrighted by the Informing Science Institute. Permission to make digital or paper copy of part or all of these works for personal or classroom use is granted without fee provided that the copies are not made or distributed for profit or commercial advantage AND that copies 1) bear this notice in full and 2) give the full citation on the first page. It is permissible to abstract these works so long as credit is given. To copy in all other cases or to republish or to post on a server or to redistribute to lists requires specific permission and payment of a fee. Contact Publisher@InformingScience.org to request redistribution permission. tional Science Foundation [NSF], 2009; Wao \& Onwuegbuzie, 2011). Nettles and Millet (2006) found that across disciplines, education ranked lowest in doctoral student publications (15\% compared to $30 \%$ ) and presentations (30\% compared to $37 \%$ ).

The nature and responsibility of doctoral students enrolled in education programs may contribute to these statistics. The 
typical doctoral education student works full time (e.g., principal, administrator, teacher), with academic responsibilities serving to intensify demands on their energy, commitment, and time (Dorn, Papalewis, \& Brown, 1996; Jimenez, 2011; Smith, Maroney, Nelson, Abel, \& Abel, 2006). Full time employment constricts students to studying part time, and research suggests that part-time doctoral students experience longer time-to-degree rates than those who are engaged full-time (Wao \& Onwuegbuzie, 2011). Attrition and prolonged time-to-degree can be costly to institutions, but devastating and demoralizing for students as a result of the financial, personal, and professional consequences (Lovitts, 2001; Terrell, Snyder, \& Dringus, 2009; Wao, 2010).

With education students experiencing the longest time-to-degree rates (NSF, 2009) and consistently high attrition rates (50\% - 70\%) (Ivankova \& Stick, 2007; Nettles \& Millet, 2006), research examining factors associated with persistence is timely and pertinent. The purpose of this study was to learn from individuals with earned educational doctorates the personal, social, and institutional factors they attributed to their doctoral persistence and degree completion. The theory of resilience and Tinto's $(1975,1993)$ student integration theory served as the conceptual framework for this study.

\section{Conceptual Framework}

At its simplest, resilience is defined as success despite adversity (Cefai, 2004; Luthar, Cicchetti, \& Becker, 2000). While resilience research traditionally focused on generating lists of risk and protective factors (see Garmezy, 1971; Werner, Bierman, \& French, 1971), resilience is now viewed as the interaction between the individual and resources and stressors in the larger sociocultural context (Clauss-Ehlers, 2008; Luthar et al., 2000). Thus, resilience research is nested within an ecological model that emphasizes contextual factors and interactions between individuals and their environment.

Given attrition statistics, beginning a doctoral degree involves risk. Brailsford (2010) observed, "There is a body of quantitative and qualitative research proving that deciding to do a Ph.D. is a high-risk strategy” (p. 15). Moreover, candidates beginning doctoral degrees in education are particularly at high risk given statistics suggesting that the likelihood that they will earn their doctorate hovers between 50\% and 30\% (Ivankova \& Stick, 2007; Nettles \& Millet, 2006). If they do persist to completion, their journey is on average longer than that of candidates in all other disciplines (NSF, 2009; Wao \& Onwuegbuzie, 2011).

The emphasis in resilience research on the interaction between individuals and their environment aligns with Tinto's (1993) integration theory which posits that graduate persistence is "shaped by the personal and intellectual interactions that occur within and between students and faculty and the various communities that make academic and social systems of the institution” (p. 231). Conversely, when students fail to become integrated into their university's academic and social communities, they are more likely to withdraw. Tinto's $(1975,1993)$ theory is affirmed through various studies examining doctoral persistence and attrition (see Earl-Novell, 2006; Herzig, 2002; Hoskins \& Goldberg, 2005; Ivankova \& Stick, 2007). The literature review and research findings from this study are organized within the framework of Tinto's student related and institutionally related factors.

\section{Review of the Literature}

Review of the literature reveals that doctoral persistence is not the result of one single factor (Bair, 1999; Gardner, 2009; Wao, 2010), but rather, an interaction of multiple factors generally categorized as student related factors or institutional factors (Ivankova \& Stick, 2007; Tinto, 1993; Wao, 2010). Student related factors and institutional factors interact and contribute to the 
level the student becomes integrated into the university, which is essential to persistence (Tinto, 1993, 1997, 1998).

\section{Student Related Factors}

A range of student related factors are associated with persistence, including demographic variables, personal attributes, motivation and goals, responsibilities, and coping skills.

Demographic variables. Demographic variables related to persistence include age, gender, ethnicity, and marital status (Strayhorn, 2005; Wao \& Onwuegbuzie, 2011). Men are more likely to finish than women, older Caucasian students are more likely to graduate than older minority students (Stiles, 2003), and married students are more likely to persist than unmarried students (Lott Gardner, \& Powers, 2009; Price, 2006).

Personal attributes. Personal attributes such as learning style, intelligence, GRE, GPA, admission interview performance, personality, and level of intrinsic motivation are positively associated with persistence (Lovitts, 2005). Student ownership of the dissertation is integral (EarlNovell, 2006), though it may depend on the nature of the program and discipline. For example, in some programs independent thought and creativity are valued, while in others, diligence and hard work may be admired (Earl-Novell, 2006). McAlpine and Norton (2006) observed that "Humanities and social sciences tend to take a more individual approach to research, whereas natural and health sciences favour more team based research. The latter approach may make students less likely to withdraw" (p. 9). Competence and being proactive are also associated with persistence (Grover, 2007). Conversely, student traits of dependency, unrealistic thought processes, and procrastination are impediments to finishing the doctoral program (Terrell, 2002).

Motivation. Motivation and goal setting are integral to doctoral persistence (Grover, 2007). Research suggests that candidates who are both personally and professionally motivated are more likely to persist (Hoskins \& Goldberg, 2005). Personal motivations are typically associated with achievement, personal goals, enjoying a challenge, and desiring the title. Professional motivations cited typically include factors associated with career advancement, such as increasing personal marketability and credibility, as well as being eligible or recognized for a promotion or raise. Motivation is related to goals and achievement, with research suggesting that goals may change over the course of degree completion. For example, Wao and Onwuegbuzie (2011) found that many students enter programs without a goal to conduct research; however, after being integrated into the program, they found that they really enjoyed research and this became an academic goal.

Responsibilities. Balancing doctoral studies with family and work relationships is a challenge for doctoral students across disciplines. In a quantitative study surveying 619 students across 78 doctoral programs, Wasburn-Moses (2008) reported that "doctoral students felt least satisfied with their ability to juggle work and family with their overall workload” (p. 265). Moreover, the time needed to devote to doctoral studies and the time away from family results in feelings of guilt, worry, and anxiety (Smith et al., 2006), leading to elevated levels of stress. Problems related to finances, health, academics, and family have also contributed to doctoral students' decisions to leave their programs. In a survey of departed students, Lovitts (2001) found that $70 \%$ cited personal reasons.

Coping skills. The ability to effectively manage and cope with stress is strongly correlated with doctoral persistence. Research suggests that candidates receiving funding (e.g., scholarships, assistantships, fellowships) experience lower levels of stress than those without funding (McAlpine \& Norton, 2006); however, stress management programs and seminars are also effective (Smith et al., 2006). There is also strong consensus that effective personal support systems help buffer stress (Smith et al., 2006; Torres \& Solberg, 2001). In particular, friendship and religion or per- 
sonal spirituality help moderate the effects of stress (Itasca, 2001; Nelson, Dell'Oliver, Koch, \& Buckler, 2001). Stress management is especially important for candidates enrolled in educational doctorates given the fact that even aside from their studies, "Educators such as school principals, administrators, and teachers generally have rather hectic schedules and a fair amount of daily stresses” (Dorn et al., 1996, p. 305).

\section{Institutional Factors}

Institutional factors (program type, structure, and curriculum) and student expectations about the relationship between these factors and their own personal and professional goals play a central role in doctoral student persistence.

Program type and structure. The type of program and program structure significantly shape doctoral student experiences and integration into the university and program. For example, attrition rates in distance programs are consistently 10\% - 20\% higher than in traditional, residential programs (Rovai, 2002). These statistics are explained by the fact that students in distance programs often experience feelings of isolation as a result of low levels of socialization and interaction with peers and faculty (Terrell et al., 2009). While distance programs are associated with lower levels of persistence, programs utilizing cohort models are associated with higher levels of persistence (Lovitts, 2001; Norris \& Barnett, 1994). Cohorts may be organized according to when students begin a program or according to research focus (West, Gokalp, Edlyn, Fischer, \& Gupton, 2011). Irrespective of the model, cohorts provide interactions with peers that foster connectivity and increase social integration, sense of belonging, and community (Lovitts, 2001; Norris \& Barnett, 1994).

Curriculum and program. Programs that account for the learning styles and needs characteristic of adult learners (Knowles, 1980) are associated with higher persistence rates. Adults are more likely to persist in programs where the curriculum is flexible and relevant to their professional practice (Hoskins \& Goldberg, 2005). Further, there are two distinct stages in most doctoral programs: coursework and the dissertation. The former is generally structured and familiar for students; the latter generally unstructured and unfamiliar (West et al., 2011). Doctoral persistence increases within programs that recognize the challenges associated with transitioning from structured coursework to unstructured dissertation writing by building a connection between coursework and skills needed to execute the dissertation (de Valero, 2001; Jimenez, 2011).

Expectations and communication. Student expectations about the program, coursework, and policies also play a significant role in persistence. Hoskins and Goldberg (2005) found that when expectations were met, few students commented or noted them; however, when unexpected events or changes took place, particularly in a series, students tended to question if there was a mismatch between their goals and the selected program. Hoskins and Goldberg (2005) defined academic match as "the correspondence between (a) student goals and reasons for pursuing the degree and (b) the program focus and the curriculum" (p. 183). Academic mismatch is an incongruity between what doctoral candidates "wanted from the program and what they thought the program was preparing them to do” (Hoskins \& Goldberg, 2005, p. 183). When student perception of mismatch reaches a certain level, or when students lack adequate information about processes and expectations, they are more likely to withdraw from the program (Golde \& Dore, 2001).

Academic mismatch can be averted with a comprehensive doctoral orientation, handbook, and effective faculty advising and mentoring. A strong doctoral orientation not only outlines program processes, procedures, and expectations, but also introduces students to the academic culture of higher education (Wasburn-Moses, 2008). Students report that effective advising and faculty support are instrumental and describe effective advisors as accessible and approachable, attributing effective faculty mentoring and sufficient input into the dissertation as the key to their success 
(Earl-Novell, 2006). Faculty support includes instrumental help (e.g., coaching, challenging assignments, encouraging student productivity in terms of publishing and presenting), psychosocial help (e.g., counseling, role modeling, empathizing), and networking assistance (e.g., helping students makes connections in the field, serving as a professional reference) (Tenenbaum, Crosby, \& Gliner, 2001).

\section{Student Integration into the University}

Resilience research and Tinto's $(1975,1993)$ student integration theory consistently point to interactions between individuals and their environments as central to fostering resilience and persistence. Specifically, academic integration and social integration are the most prominent themes in the literature (Lovitts, 2001; Tinto, 1997), though researchers also identify the importance of economic integration (Wao, \& Onwuegbuzie, 2011).

Academic integration. Academic integration is fostered through learning communities where shared knowledge (a shared educational experience) and shared knowing (sharing the experience of learning) occur (Tinto, 1998). Academic integration is generally dependant on student relationships with faculty and advisors (Earl-Novell, 2006). Moreover, increased academic integration results in "greater acquisition of knowledge and development of skills" (Tinto, 1997, p. 600). On the other hand, program mismatch and isolation lead to low levels of academic integration, leaving students susceptible to attrition (Golde, 2005).

Social integration. Opportunities for students to participant in learning communities and the construction of shared knowledge results in greater social integration while also fostering the acquisition of knowledge and skills, thereby bridging the "academic-social divide" (Tinto, 1997, p. 610). Social integration-feeling a sense of connection and community with faculty and peers-is an important factor in doctoral persistence. Connection is defined as "the establishment of a relationship or the failure to do so, with faculty or fellow students and a judgment of the quality of that relationship" (Hoskins \& Goldberg, 2005, p. 183). Sense of community is an important element of feeling connected and is associated with mutual interdependence, feelings of belonging, trust, and dedication to the community (Rovai, 2002).

Relationship with peers is a large element of social integration (Tinto, 1997). Research suggests that "a peer mentoring program that matches students with those who have had similar experiences may assist students in understanding and successfully navigating their own experience" (Gardner, 2008, p. 135). Additionally, through fostering socialization and integration with peers, cohorts serve to counter isolation (Jimenez, 2011). Social integration is particularly important during the dissertation phase, which tends to be a solitary and socially isolating process (de Valero, 2001).

While positive relationships with peers are valued, doctoral students view relationships with faculty as essential (Hoskins \& Goldberg, 2005; West et al., 2011), specifically the role of the dissertation chairperson (Maher, Ford, \& Thompson et al., 2004; Pauley, Cunningham, \& Toth, 1999; Tinto, 1993). In fact, relationships between candidates and chairs "can spell the difference between completing and not completing a doctoral program” (Smith et al., 2006, p. 20). Persistence is further fostered when students are provided opportunities to research, write, and present with faculty (Hoskins \& Goldberg, 2005). On the other hand, miscommunication with faculty and frustrations with universities have been identified as contributors to attrition (Lovitts, 2001).

Economic integration. Wao and Onwuegbuzie (2011) discussed the importance of economic integration, that is, the "degree to which student's financial needs are met while pursuing the doctorate” (p. 117). Economic integration is essential given research suggesting that irrespective of program, students who self-finance their studies are less likely to persist (Earl-Novell, 2006). University sponsored fellowships and assistantships influence economic integration and increase 
persistence and decrease time-to-degree rates (Earl-Novell, 2006; Wao \& Onwuegbuzie, 2011). Lovitts (2001) found that $20 \%$ of students in her study cited financial reasons for their program departure.

\section{Conclusion}

Review of the literature reveals that persistence in doctoral candidates is the result of the individual and his or her interaction with the social and institutional environment. Prior research has focused specifically on women (Castro, Garcia, Cavazos, \& Castro, 2011; Maher et al., 2004), mathematics doctoral students (Earl-Novell, 2006; Herzig, 2002), counselor education students (Hoskins \& Goldberg, 2005), and students who have withdrawn (Golde, 2005). Ivankova and Stick (2007) examined factors related to doctoral persistence in an educational leadership program, but the focus was on understanding factors specific to students studying via distance education, with a particular focus on distributed programs. Further, research has generally focused on implications for doctoral faculty and programs with a focus on improving institutional structure and program outcomes (see Golde, 2005; Herzig, 2002; Maher et al., 2004; McAlpine \& Norton, 2006; Terrell et al., 2009). Few studies focus on implications or recommendations specific to prospective or current doctoral students.

Additionally, research on doctoral persistence has generally been conducted using quantitative methods, typically using survey data, and seldom have the stories of those who have successfully navigated the doctoral journey been collected qualitatively. Researchers have called for more doctoral persistence research using qualitative methods of inquiry (Hoskins \& Goldberg, 2005; Wao \& Onwuegbuzie, 2011). Recognizing the paucity of research in this area, we investigated the phenomenon of doctoral persistence through a qualitative analysis of the narratives of individuals who successfully completed doctorates in the field of education and were successfully serving in the discipline (e.g., administrators, higher education faculty).

The purpose of this study was to analyze the narratives of successful doctoral candidates in order to uncover the personal, social, and institutional factors and contexts leading to the completion of the doctorate; thereby, providing recommendations for prospective or current doctoral students. The central question guiding this study was, what factors do individuals with terminal degrees in education attribute to their doctoral persistence?

\section{Method}

\section{Design}

It has been noted that "students are central to the doctoral undertaking. Yet, theirs is the voice that is least heard” (McAlpine \& Norton, 2006, p. 6). A qualitative phenomenological approach was selected for this inquiry given the emphasis on giving a voice to participants by exploring the meaning they attribute to their persistence in an educational doctorate. Creswell (2007) explained that "the basic purpose of phenomenology is to reduce individual experiences with a phenomenon to a description of the universal essence" (p. 58). The specific phenomenon this study sought to describe was doctoral persistence, operationally defined for the purpose of this study as the successful completion of a doctoral degree in the field of education.

Individual experiences with the phenomenon were captured through standardized open-ended interviews (see Table 1). The standardized open-ended interview is conducted in such a way that each participant is asked the same set of questions in a prescribed sequence (Patton, 1990). Given the inductive nature of qualitative research (Lincoln \& Guba, 1985), questions were designed to be broad and open-ended. Questions 1 - 3 served to ensure participants met the criteria for the study, and questions $4-9$ were designed to elicit responses related to participant experiences, 
motivations, and identification of factors attributed to persistence. Because questions were developed in advance and each participant was systematically asked the same set of prescribed questions, effects from using multiple interviewers were minimized (Patton, 1990).

Table 1. Standardized Open-Ended Interview Questions

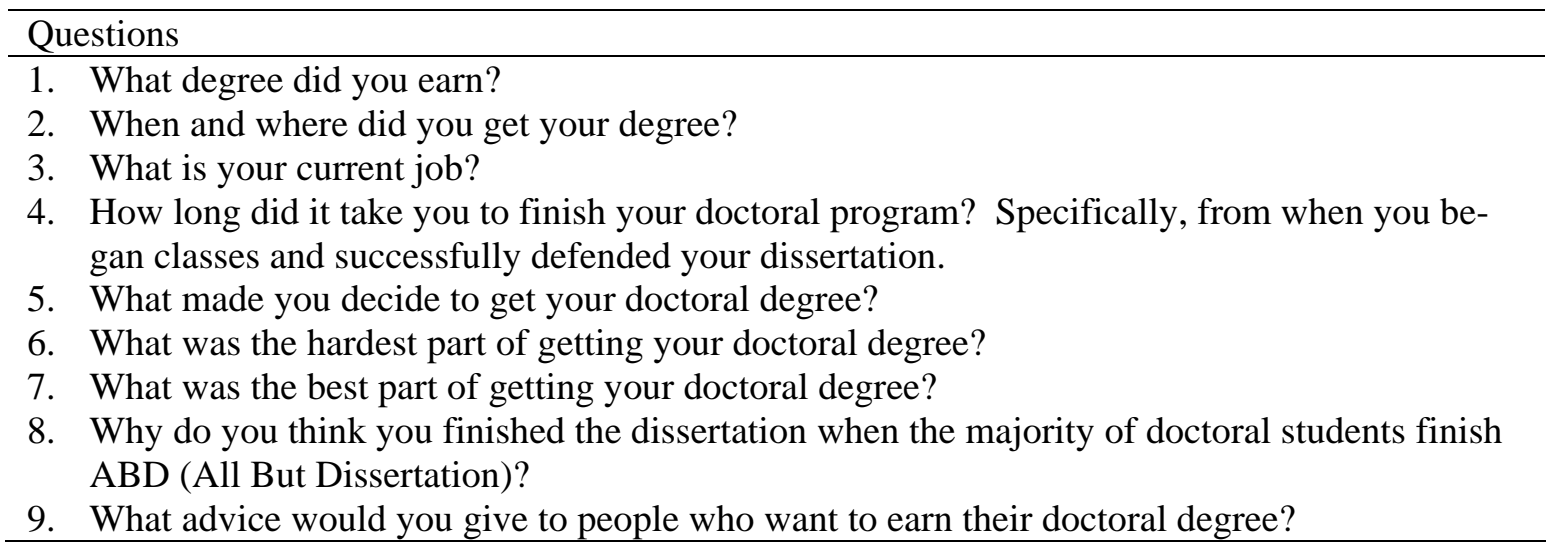

\section{Procedures}

Interviews were conducted from April through December 2010 by doctoral students enrolled in an online qualitative research methods class at a private university in the Southeast United States. Each doctoral student was provided with instruction and guidance on how to conduct interviews from a faculty mentor with expertise in conducting qualitative research. Each doctoral student was instructed to purposefully select two participants meeting the sample criteria: (a) completion of a doctoral degree in Education, and (b) individuals currently serving in the field (e.g., university faculty, school administrators, policy makers, etc.). Interviews were conducted in person or through videoconferencing (e.g., Skype) at sites across the United States. Each interview was audio recorded, and the doctoral students were instructed to transcribe the interviews verbatim. We accessed the manuscripts in the form of archival data after gaining permission from the Institutional Review Board (IRB) of the university where the doctoral students conducting the interviews were enrolled. Doctoral student and participant identifying information were removed from the transcripts before we received them.

\section{Participants}

While the IRB approved access to approximately 200 transcripts, transcripts were carefully screened to ensure the participants met the established selection criteria and participant selection ceased when thematic saturation was achieved (Patton, 1990). Thematic saturation was determined when analyses of additional transcripts revealed no new or variant themes from those generated from analyses of previous transcripts. Data from 42 women (55.26\%) and 34 men (44.74 $\%)$ with earned doctorates in education and employed in the field was analyzed in this study. Fifty five (72.37\%) of the participants identified themselves as Caucasian, 16 (21.05\%) African American, 2 (2.63\%) Latino, 2 (2.63\%) Asian, and 1 (1.32\%) “Other.”

\section{Data analysis}

Analysis procedures followed Moustakas' (1994) approach for conducting a transcendental phenomenological study. In accordance with these procedures, we were intentional to first identify and purposefully set aside (i.e., "bracket") our own experiences with the phenomenon in order to focus on the experiences of the study participants. We made efforts to suspend our personal 
judgment about the phenomenon and examine the data with a fresh lens by journaling about our own experiences prior to analysis. In this exercise we chronicled our own doctoral journeys and our subsequent experiences serving as doctoral faculty in a large program for students earning Doctorates of Education. Throughout our analysis of the data and at the conclusion of our study, we examined and cross examined our own narratives and the emerging themes from our participant narratives to purposefully suspend our own perceptions on the phenomenon in order to share our participants' stories and the meaning they attributed to them.

The second step in the analysis involved reading and re-reading the interview transcripts, reducing data into significant statements, and developing themes from combining these meaningful sentences or quotes. From these themes, we developed textural descriptions of what participants experienced in the successful pursuit of their doctoral degrees, followed by structural descriptions of the contexts and conditions that led to their success (Moustakas, 1994). Finally, we used these descriptions to construct a description of the essence of the phenomenon of study (Moustakas, 1994); that is, persistence leading to the successful completion of a doctoral degree in the field of education.

\section{Results}

The purpose of this inquiry was to examine persistence factors associated with the successful completion of a doctoral degree in the field of education The significant themes generated from the analysis of participant responses are organized and presented through (a) textural descriptions: "What" participants experienced; (b) structural descriptions: "How" participants persisted; and finally, (c) a composite description of the "essence" of the phenomenon (Creswell, 2007; Moustakas, 1994).

\section{Textural Description: "What" Participants Experienced in their Doctoral Journey}

Completion of a doctoral degree is a significant accomplishment associated with considerable rewards, both personal and professional. However, for the participants in this study, the accomplishment did not come without a price. The participants experienced significant adversity in their doctoral journey before experiencing the rewards of a successful dissertation defense and walking in their graduation ceremony. The following themes concerning the lived experiences of the participants emerged in their descriptions of the pursuit of a doctoral degree in education: (a) personal sacrifice, (b) intervening life experiences, and (c) dissertation challenges.

Personal sacrifice. Personal sacrifice was a significant part of each participant's journey to degree completion. One participant related, "I sacrificed a lot, maybe too much for about three or four years, there were no summers for me, it was writing, there were no weekends for me, it was writing, there were no grand vacations, it was writing and putting the dissertation together." Another participant remarked, "Basically, for 3 years, all of my spare time was spent on my dissertation, researching, writing, and classwork." For another, "The entire process was difficult. It takes up your entire life." For one participant, personal identity was lost:

I felt like I wasn't even a person. I couldn't read what I wanted, I couldn't have any kind of a social life if I wanted to. It's like your whole life is this project and everyone keeps saying 'finish, finish,' but if you are going to, you have to set aside any kind of personal things.

Many participants sacrificed sleep in order to cope with the multiple demands on their time. One participant recalled, "I used to stay up to 2:00 a.m. trying to get assignments done after they 
[children] went to bed." Another shared, "there were nights that I literally worked from 6:00 that evening until 6:30 the next morning, changed my clothes, and went to work.”

Sacrificing time with spouses, children, and friends was a prominent theme in participant discourses, and effects on family life and family members, particularly children and spouses were frequently noted. One participant felt like "an absent parent," explaining that "anytime I wasn't working on that blasted dissertation, then I was trying to sleep." Several participants recalled missed opportunities to watch their children play sports and regretted not returning to school earlier, ideally before having children. Participants' spouses also felt the toll. A caring husband related,

I can't tell you how hard that was, like seeing the look on your wife's face when she asks you to watch a movie with her on a Friday night and you tell her that you can't because you have a paper to write. That look breaks my heart just thinking about it.

All of these sacrifices took an emotional and physical toll on participants. One participant recollected, "there were moments when I was overwhelmed with a level of stress that I was not expecting." Another participant clearly struggled with "the guilt associated with doing something where you think you're doing it at the expense of others." Perhaps as a consequence of sacrificing time with family and friends, loneliness was also a pervasive theme. With the general lack of sleep and the emotional stress from trying to effectively balance a myriad of responsibilities, several participants noted how susceptible they were to "burnout" and "breaking down."

Intervening life experiences. A second theme that emerged in participant discourses related to unmet expectations concerning the timeframe of progressing from initial coursework to final defense. A myriad of intervening life experiences delayed some participants, such as a spouse being laid off from work, a job promotion or reassignment demanding more time and focus, a new marriage, finding adequate childcare, or helping plan a daughter's wedding. Several participants noted that having a child in the middle of the process impeded their progress; this was more prominently noted by female participants, but a few males noted it as well. One participant related, "having a baby in between. That was hard. I remember being so tired and having to write papers and go to class." Other factors impacting progress were more internal in nature, including poor time management, organizational deficits, lack of motivation, and tendencies toward procrastination.

Death and illness of either a loved one or a dissertation committee member delayed the process for multiple participants. One participant had to take care of her "ailing mom," another "lost a year" because her husband had a heart attack and her mother died the same year. Another participant had a miscarriage. Several participants noted delays after losing a dissertation chair or committee member in the middle of the process.

Dissertation challenges. Aside from institutional/program related obstacles impeding progress (e.g., learning new systems and technologies, the passage of comprehensive exams, or advisors taking sabbaticals or retiring), delays and challenges associated with the successful completion of the dissertation presented some of the greatest obstacles participants needed to overcome. Interview question 6 required participants to recount the hardest part of earning their degree. Across participants, responses almost unequivocally related to the challenges associated with completing the dissertation. Subthemes in responses included challenges with the autonomous nature of the process, time management, research and statistics, mastering the writing process, and challenges associated with dissertation chairs and committee members.

While participants acknowledged that coursework was time consuming, entering the dissertation phase was a very different experience. In particular, participants identified the shift from being instructor-led through the familiar structure of coursework to being largely self-directed in the 
unfamiliar and unstructured dissertation process as a formidable challenge. As discussed by one participant, "once you get done with your coursework it's a whole new world. Nobody hanging over you, there's no deadline- you want to work on it for the next seven years, work on it for the next seven years." Another participant related, "as a student, you know, it's really organized but boy when you get to the dissertation phase now it's more self paced and it's you and your advisor, your main advisor, and that's it.”

One of the challenges associated with the autonomous nature of the dissertation process was identifying a researchable topic of interest. One participant noted that the challenge was "not so much writing the dissertation but coming up with a topic to write on." Another acknowledged "making that final decision about the dissertation [topic]" was the greatest challenge.

Finding time to work on the dissertation emerged as a considerable challenge and a prominent subtheme related to the dissertation process. Participants found the sheer amount of time necessary to complete the dissertation immensely challenging: "It was extremely time consuming!" "it takes up your entire life," "it wasn’t the work that was so hard ... it was just the amount of time it took to complete all of it.” A significant difficulty was balancing commitments to work and family while finding time to devote to the process. One participant explained, "it wasn't the work ... it was just being able to fulfill my responsibilities with work and as a mother."

Technical aspects related to the development of the dissertation also presented challenges. Several participants noted difficulty with "the scholarly writing to justify the research." Participants frequently struggled with the nature of the writing process and the "constant re-writing." Statistics also presented a challenge, especially for participants who conducted quantitative studies. One participant shared, "My forte is writing curriculum, assessment, and grants. Statistics was especially challenging for a literary person." Another quite simply stated, "I hate statistics!"

While balancing priorities, working through the writing process, and conducting statistics presented a challenge for various participants, the most frequently noted challenge in participant discourses related to difficulty with dissertation chairs and committee members. Frustrations typically pointed to chairpersons who were "challenging to work with," "offered very little guidance in the process," or left participants insufficiently prepared for a defense.

Obtaining a chair and forming a committee proved to be a challenging process for some. One participant elaborated, "first my advisor went on sabbatical for two years, and then one of the professors on my panel died and another retired so I had to build almost an entirely new panel." Participants who graduated from online programs had their own unique challenges related to forming a committee. One participant noted, "It is difficult to form working relationships." Online graduates also related that writing the dissertation from a distance was challenging because they "missed the interaction with peers and professors."

Further, the "subjective and sometimes confusing information that one might receive from one's advisor in the dissertation process" was another significant challenge. Participants noted challenges with "satisfying four different committee members." One participant recalled,

I almost quit again right before the defense. ... It wasn't the tweaking required after the defense; it had to do with lack of direction and uniformity from the professors or their changing their mind when you think you are finished.

Additional challenges cited included receiving inadequate guidance about the process, needing to learn new technology, and staying disciplined, motivated, and organized.

Evidenced through these descriptions of the challenges participants' experienced, walking the road to completion of a doctoral degree is clearly an intensely grueling, challenging, and sometimes lonely journey. Candidates clearly experienced adversity. However, the candidates inter- 
viewed were also resilient, and through a range of coping mechanisms that served to increase their social and academic integration into the university, were able to persist and achieve their personal and professional goal of earning a doctorate.

\section{Structural Description: "How" Participants Persisted}

As demonstrated through the structural description of the settings and contexts influencing "how" participants experienced the phenomenon of doctoral persistence (Moustakas, 1994), a web of contextual factors emerged in the participants' descriptions of their experiences. These factors included personal factors (i.e., motivations for pursuing the degree, reasons for persisting, strategies for dissertation completion), social factors (i.e., support systems and coping mechanisms), and institutional factors (i.e., program characteristics).

Personal factors. Reasons for beginning an educational doctorate were varied and were both personally and professionally motivated. The completion of a doctorate was the fulfillment of a personal goal or lifelong dream for many internally motivated participants. One participant shared, "I just wanted it." Another related, "I’ve always been motivated and value education. I knew I would get it someday." Other participants saw earning a doctorate as a personal challenge and a way to prove something to themselves. One participant sustained a severe head injury and as a result experienced memory loss and "could not read a paragraph in the New York Times." As this participant related,

there was a real personal challenge there. ... I just wanted to see if I could bring my brain back to the point where I could complete a doctorate, so I probably had a different level of drive than someone who needs it for their job. I mean I totally did it for personal reasons, and the side benefit was, yeah, my pay went up, but that was not my motivating factor.

A salient theme in many participant responses addressing why they decided to pursue the degree was simply for the love of learning. Responses included, "I just love school," "I like doing a lot of research and keeping up to speed on things," "enhanced knowledge and credibility," "I like research," "personal growth and learning," and "I have always been a lifelong learner."

Participants were also motivated by familial or relational reasons. Several participants had a sibling or parent who had earned a doctorate who served as a motivator and model for them. One participant explained, "My brother has his doctorate, and I just wanted to keep up with my brother and make my parents proud." Other participants pursued the degree to make a family member proud: "my dad is very into education. . . . there was an aspect of want[ing] to please my dad." For some, the encouragement came from a spouse, a peer, a colleague, a professor, or a person in a supervisory position over them. Other participants were motivated to earn the degree in order to serve and to improve the lives of others. One participant shared, "I felt that an additional degree will allow me to serve a larger population in the education arena." Another noted, "I was also inspired by the children of the North Mariana Islands and the research in education for quality education.” In response to low expectations placed on them by others, a few participants simply wanted to prove themselves to someone or to break a stereotype by earning the degree.

Professionally motivated reasons for earning a doctorate included increased marketability, credibility, and compensation. For many participants, earning a doctorate opened up career opportunities otherwise closed to them. One participant related, "I knew I wanted to be an administrator." Though focused on higher education rather than administration, one participant related, "you have to get a doctorate if you wanna stay on and advance through the ranks and become a full professor." Other noted career aspirations included becoming a superintendent and earning an appointment as United States Secretary of Education. 
Participants also discussed monetary incentives and social recognition generally associated with promotions and new appointments. One participant simply stated, "it was the only way I was going to get a pay increase.” Another participant noted that the raise associated with the degree would allow him to send his children to private school. For other participants, increased credibility, the "recognition of being a doctor," and the status associated with the title were significant motivators.

While some participants cited only personal factors or only professional factors in their responses, a significant number of participants noted both factors as they explained their motivation for pursing the degree. Responses identifying personal and professional reasons were common. For example, "I wanted more knowledge and I also wanted the opportunities that the degree would offer me," "an interest in learning and an interest in moving into higher level of administration," and "it would give me better credibility. . . and it would give me something to keep my mind active.”

Similar to reasons for beginning the degree, reasons for persisting were also influenced by both an interaction of personal and professional factors. Personal traits and characteristics were most frequently noted as intrinsic reasons for persisting. Participants used the following adjectives to describe themselves: "goal oriented," "stubborn," "structured," "persistent," "committed," "determined," "self-motivated," "disciplined," "independent," "mature," “competitive,” and "detailed." For many, it was simply refusing to quit: "If I start something, I want to finish it.” For others, it was to accomplish something personal: "I needed to accomplish something for myself." Being able to accept criticism and respond positively to feedback was a salient theme related to persistence. One participant explained, "I think that people with a personality that can accept criticism and change and look forward to that challenge are able to finish." Another participant elaborated, "the harder they [faculty] pushed me, the more determined I became."

Externally related reasons for persisting were often associated with resources already invested. As one participant related, money was a significant factor: "my husband and I are very frugal, very practical, and the notion of investing money and then having it go to waste just was not something we would do." Time and energy were also factors: "There was NO way I was going to put all that time, energy, and money into a program and then NOT finish! That wasn't an option for me.”

In order to succeed, participants recognized the need to make structural changes in their lives. Several participants credited their success to quitting full time jobs or reducing hours in order to "focus on just being a student." Others noted the importance of organization and time management. Keeping calendars, making schedules, writing timelines, and developing plans and goals were all factors associated with persistence. One participant admonished,

Have a plan! Work through the details of when you are going to attend class, who is taking care of supper on those nights, and when is my study time, and so on. The little details are the parts that cause people to lose their focus and not finish.

Concerning goals, one participant advised,

have some goals, and have some completion goals in mind. I want to complete coursework by this date. I want to complete comprehensive exams by this date. I want to have a proposal for the dissertation by this date. I want to have a dissertation to defend by this date. Have realistic goals.

Every participant was able to articulate a strategy or set of strategies that enabled them to persist through the dissertation process. First, it began with selecting a good dissertation topic: "Find a topic that interests you and find it early," "This process will consume a lot of your time, lack of interest will kill you," "I think one of the reasons I was able to finish quickly is that I came in with a very clear idea of what it is I am trying to do.” Several participants noted having a strong 
foundation in their topic by the time they reached the dissertation stage was important to their success:

if you can identify your dissertation topic relatively early on you can do pieces of the dissertation as you move through the classes and suddenly when you actually get to that transition where you focus on the dissertation you know maybe a third of the project is basically done and uh I mean you still have to see it through to completion, but that's a big head start from starting from scratch.

Finally, participants attributed their success to working continuously and systematically on the dissertation without taking prolonged breaks. One participant related, "I think I did not stop. I just continued. . . . I didn't put it aside, I guess. I think sometimes when you do that it's hard to get back to it.” Another participant emphasized, “the day you relax and don't take that class or don't pay for those dissertation hours, that's the day that you don't finish because you are back to that environment of being relaxed again.” Refusing to stop and keeping the pressure on oneself translated into working on the dissertation regularly: "I set aside two hours each evening during the week to work on my course work, and when I began my dissertation, I wrote at least two to three pages a day.”

Social factors. Participants associated an array of informal and formal support systems with their persistence. For some, it was having help with childcare and household duties. Many participants cited the significant role a supportive spouse, parent, or friend played in their emotional stability. In terms of academics, participants noted leaning on friends or family members who were "strong in grammar" or could help with statistics, while other participants noted the value of formally hiring an editor or a statistician.

Second, the importance of carefully selecting a chair and committee members was repeatedly noted. While difficult or inexperienced chairs proved to be one of the biggest challenges participants experienced in the dissertation process, the right chair proved to be a great contributor to participants' success, because as one participate shared, "Your advisor can provide the energy and guidance for you to be successful." It was equally important for participants to carefully select committee members: "Getting your committee to work together is important. Think about this when you select committee members. Pick people who can work together."

Institutional factors. Program characteristics were frequently associated with persistence. Many participants attributed doctoral course work prior to beginning the dissertation to their degree completion, specifically, programs with rigorous research and writing courses that prepared them for the challenges associated with the dissertation. Faculty who were "knowledgeable" and "high quality" were also identified as integral to success. Finding a reputable program with the "same values that you [have]" was also important, along with picking a program compatible with life circumstances and learning styles (i.e., academic match). For some, online programs were a blessing in that they allowed participants to pursue the degree without needing to relocate their family or change jobs; for others, enrollment in traditional (residential) programs allowed them to form meaningful and collaborative relationships with peers and professors.

Whether enrolled in a distance or traditional program, many participants noted the encouragement and support they received from being in a cohort. Cohorts provided the participants' opportunities to commute to class together, share accommodations, collaborate professionally, and study, pray, brainstorm, and laugh together. Overall, participants were strong proponents of the cohort model. One participant related, "You need to have people within your cohort, people that you work with that you can bounce things off of, relieve stress, laugh, joke." One participant related,

I am a strong proponent of the cohort model - I think that the doctoral journey can be a very lonely journey if you don't have the support. . . . So having that, that strong cohort 
and members of your cohort who are in this journey and who are willing to share their experiences, to me was the key.

\section{Essence of the Phenomenon}

Just as participants identified common challenges in the process and similar resilience mechanisms for persisting, their feelings and emotions upon degree completion were also consonant. After a successful dissertation defense, participants voiced experiencing a tremendous sense of relief and accomplishment. Being at "the highest level of [their] field" provided them significant satisfaction, accompanied by "relief that it was indeed over." For some, "successfully defending was the best part" of earning the degree. For others, it was the joy of walking in the graduation ceremony in front of their loved ones.

Earning the initials behind their name or the title "Dr." was also a highpoint for many. One participant shared, “now my mail comes with 'Dr.' in front of my name.” For some, the sense of accomplishment came from the additional opportunities associated with the degree. One participant explained, "the best part of getting the doctorate degree is because your credential allows you now to actually advocate now and move forward.” For a subset of participants, their sense of accomplishment in the title was derived from the gain in knowledge and the development of new skills. For many participants, the experience was transformative in nature; one participant shared, "you learn so much about yourself and how to become a better person, and a leader in my case."

When participants were interviewed, they worked in different states and professional settings across the United States and earned their degrees from varying institutions across the span of five decades (Participant 3 - 1976; Participant 36 - 2011); however, each participant shared one common experience-doctoral persistence, evidenced by the completion of an educational doctorate. Though the contexts differed and motivations for pursuing the degree varied, participants all cited various personal sacrifices along the way, often found their completion expectations to be unrealistic due to a myriad of intervening factors, and largely found the dissertation to be the most challenging aspect of the degree completion process. However, because they were both personally and professionally motivated to begin the degree, had compelling reasons to persist, developed an array of resilience mechanisms, and generated strategies for dissertation completion, these participants evaded becoming an attrition statistic, unlike presumably half of their peers (Ivankova \& Stick, 2007; Nettles \& Millet, 2006), and currently hold a terminal degree in their discipline.

\section{Discussion}

Evidenced through the textural descriptions of what successful doctoral candidates experienced, findings from this study affirm prior research suggesting that the doctoral journey can be a lonely, stressful, and challenging process (de Valero, 2001; McAlpine \& Norton, 2006; Smith et al., 2006). The structural descriptions of how the participants persisted to degree completion are also consistent with prior research and Tinto's (1998) theory positing that "the more academically and socially involved individuals are - that is, the more they interact with other students and facultythe more likely they are to persist” (p. 168). Paralleling prior research (de Valero, 2001; Gardner, 2009; Jimenez, 2011), participants credited factors associated with social integration - cohorts, approachable advisors, personable and supportive dissertation chairs - as strong reasons for their persistence. Academic integration for the study participants was fostered through academic match (Hoskins \& Goldberg, 2005), with participants citing program type (e.g., distance or residential courses), structures (e.g., cohort models, connections between course work and the dissertation), and faculty (e.g., knowledgeable and experts in their field) as factors associated with their persistence. Participant insight into the essence of doctoral persistence, that is, feeling transformed by the experience of earning a terminal degree and the knowledge and credibility associated with the 
title “Doctor," affirm Grotberg's (2003) observation that individuals demonstrating resilience are “transformed by experiences of adversity” (p. 27).

\section{Implications}

While the findings generated from this study generally reinforce prior research, most studies on doctoral persistence have been conducted with the purpose of improving institutional structures and program outcomes (see Golde, 2005; Herzig, 2002; Maher et al., 2004; McAlpine \& Norton, 2006; Terrell et al., 2009). However, the purpose of this study was to discuss implications and provide recommendations for prospective students or students currently engaged in the doctoral process. The following is a summary of experiences that can be anticipated in the successful pursuit of a doctoral degree:

Sacrifice. Time with spouses, children, and friends, will be greatly compromised, and opting out of important events (e.g., children's sports activities, vacations, social events) in order to attend to coursework or work on the dissertation is to be expected. Candidates also should be prepared to sacrifice sleep, reduce job responsibilities, and forfeit or significantly limit hobbies and leisure activities (e.g., personal reading, watching movies, attending sports events).

Intervening life experiences. One or a combination of the following may impede progress: a birth, death, illness, marital union, job loss, job promotion, faculty sabbatical, and a myriad of personal limitations (e.g., disorganization, procrastination, ineffective time management, lack of motivation).

Dissertation challenges. Completing the dissertation will very likely be the most challenging aspect of earning the degree. Challenges may be associated with identifying a motivating and researchable topic, forming a compatible dissertation committee, conducting statistics, learning new technologies, and mastering the technical and analytical aspects of the writing process. Further, the shift from being instructor-led through coursework to autonomous and self-directed during the dissertation process may be a very difficult transition and a different set of strategies may need to be employed during this stage of the degree than during coursework. Finally, balancing family and work related responsibilities while carving out time to work on the dissertation will be challenging and may be associated with feelings of guilt and loneliness, leaving candidates susceptible to breakdown and burnout.

\section{Recommendations}

While adversity is expected and challenges assured (Brailsford, 2010), they are not insurmountable. With a clear conception of the rigorous nature of the process and a strategic plan, individuals can adapt to the sacrifices, overcome the challenges, and persist to completion (Lovitts, 2001). The following is a list of recommendations grounded in the data collected from this study's participants and reinforced in existing literature for individuals considering or currently enrolled in a doctoral program:

Identify personal and professional motivations for pursuing the degree. Professional incentives such as the promise of a raise, the hope for a promotion, and the recognition derived from a new title may be compelling reasons to begin the degree, but on their own will likely not be sustainable. It is personal (intrinsic) motivations (e.g., feeling "called" to earn the degree, the love of learning, seeing the process as a personal challenge, gaining new skills and knowledge that translate into serving others) that will carry an individual through to a successful defense and to earning a doctoral degree. It is important to be able to identify reasons to persist when challenges come (Grover, 2007; Hoskins \& Goldberg, 2005) and have clear and compelling reasons to continue (e.g., time and money already invested, determination to accomplish a goal, wanting to prove to themselves or someone else that they could do it). 
Ensure academic match. Prospective candidates should select a program compatible with personal and professional goals and expectations (Castro et al., 2011; Hoskins \& Goldberg, 2005; Levine, 2007). Candidates should carefully consider the advantages and disadvantages of distance and residential programs, and look for a reputable program that meets their unique needs as an adult learner (Knowles, 1980). Candidates should also consider selecting a program with a cohort model or peer mentoring program (Gardner, 2009). Cohorts provide opportunities for peer support and social integration that foster a sense of belonging and community, which are associated with doctoral persistence (Jimenez, 2011; Lovitts, 2001). If the most compatible program does not employ a cohort model or peer mentoring program, candidates should consider developing informal support systems through social networking technologies such as Facebook and LinkedIn. Further, doctoral courses are often designed with the adult learner in mind, recognizing that they are optimally engaged in the learning process when information is relevant and practical (Knowles, 1980). When applicable, candidates should focus self-selected research papers on topics related to the dissertation interest.

Ensure social-personal match. One of the most consistently identified factors cited in studies of doctoral persistence is the role of faculty in the doctoral journey, specifically the role of the dissertation chairperson (Maher et al., 2004; Smith et al., 2006; Tinto, 1993). Findings from this study affirm this research, suggesting that when selecting a dissertation chair person and committee members, doctoral candidates should consider personality and communication style in addition to faculty expertise and experience, carefully considering the inter-relationships and dynamics of the team. The nature of a candidate's relationship with his or her dissertation chair can have a tremendous impact on the progression of the dissertation (Lovitts, 2001).

Develop personal support systems. First and foremost, spouses, children, parents, and friends need to understand the level of sacrifice involved and may need to be willing to take on additional roles and household duties (e.g., cooking, cleaning, babysitting, editing) to support the candidate for a season. However, this does not mean candidates should neglect their loved ones or fail to implement plans to invest in and safeguard these relationships. While marital stability is identified as an important completion and time-to-degree factor (Lott \& Gardner, 2008; Price, 2006), financial stress, change of roles, lack of leisure time, and poor communication can ultimately lead to divorce (Bergen \& Bergen, 1978; Cao, 2001; Giles, 1983; Middleton, 2001; Norton, Thomas, Morgan, Tilley, \& Dickins, 1998; Williams, 1977). Hence, candid conversations need to take place about the personal and collective sacrifice necessary for progression, and how each individual in the family or support unit will work toward the common goal of seeing the candidate complete the process. Conversely, candidates need to make concerted efforts to maintain their previous roles (e.g., husband/wife, father/mother, son/daughter, friend) to the greatest extent possible while balancing the responsibilities associated with their role as a doctoral student (Hyun, 2009; Norton et al., 1998).

Set realistic goals and implement strategies to reach them. With input from loved ones and faculty advisors, candidates need to develop realistic timelines for course completion, comprehensive exams, proposal, and final defense. To attain these goals while maintaining aforementioned roles, candidates need to organize their schedules to allot time on a regular basis to study, write, reflect, as well as remediate possible skill deficits (e.g., statistics, English composition). Candidates need to establish physical workspaces at home or work that allow optimal focus and minimal distraction. Bibliographic programs may need to be acquired (and learned) or systems created for storing and organizing resources. These organizational systems are essential when transitioning from the more structured stage of coursework to the more unstructured dissertation phase (de Valero, 2001; Jimenez et al., 2011; West et al., 2011).

Seek opportunities for economic integration. With many students citing financial hardship as the explanation for their departure (Lovitts, 2001), candidates should seek opportunities for eco- 
nomic integration such as scholarships, fellowships, and assistantships (Wao \& Onwuegbuzie, 2011). Though most students earning educational doctorates continue in their profession while engaging in doctoral studies (Jimenez, 2011; Smith et al., 2006), to achieve a healthy balance between family and studies, depending on personal and professional goals and timelines, candidates may need to consider reducing their work week or even cease working for a season in order to dedicate and immerse themselves in the process or to take advantage of opportunities for professional growth and economic integration (e.g., fellowships, assistantships, teaching appointments, funded research). Candidates should also be prepared to make an investment over and above tuition and course fees. Contracting additional childcare, house help, or hiring a statistician or editor may be necessary.

\section{Limitations and Delimitations}

The study has limitations due to its reliance on archival data and the use of multiple doctoral students in the data collection process. Primarily, our inquiry was limited to the data available. There are additional questions we would have included in the interview guide given our review of the literature on doctoral persistence. Further, qualitative research is emergent in nature (Lincoln \& Guba, 1985), and the researchers are the primary instruments in the data collection and analysis. If we personally conducted the interviews, we may have asked additional probing questions or prompted for elaboration on certain responses. As we did not personally select or interview the participants, we assumed honest reporting on the part of the participants and accurate recording by the doctoral students.

We delimited this study to focus on a purposeful sample of professionals with earned educational doctorates serving in the field of education. Consequently, the implications and recommendations discussed may not be transferable to doctoral candidates in other disciplines as prior research on doctoral attrition and persistence suggests that program characteristics, the nature of faculty mentoring, time to degree completion, and attrition rates vary greatly across disciplines (de Valero, 2001; Golde, 2005; Rodwell \& Neuman, 2008; Wao, 2010). The focus of the study was also on those who persisted and earned the degree rather than non-completers; thereby, excluding representation of approximately half of the population of those who begin a doctoral degree. While the representation of women (55.26\%) and men (44.74\%) was satisfactory, transferability of findings is limited as the majority of the sample was Caucasian $(72.37 \%)$.

\section{Conclusion}

With approximately one out of every two doctoral students failing to achieve their goal of earning a terminal degree in their field (Berelson, 1960; Bowen \& Rudenstine, 1992; Council of Graduate Schools Ph.D. Completion Project, 2008; Smallwood, 2004), individuals contemplating the process should recognize the risk (Brailsford, 2010) and acknowledge the challenges and sacrifices associated with doctoral persistence. They also need to be knowledgeable of and intentional to employ empirically validated strategies associated with persistence. Specifically, they should seek ways to become socially, academically, and economically integrated into their university and program.

Through the narratives of 76 individuals with earned doctorates in the field of education, we provide a general description of the essence of the journey and identify strategies and coping mechanisms associated with persistence. By understanding what doctoral students experience in the process and what measures they took to persist, future students may be better prepared for the challenges and setbacks they may experience, which should enable them to (a) make more knowledgeable and informed decisions about beginning the degree and selecting a program, and (b) identify and establish the support systems necessary to become socially, academically, and economically integrated into their university, and therefore increase their potential to persist. 


\section{Dedication}

This research was conducted in honor of Dr. Jill A. Jones - our colleague, our mentor, our friend. Although Jill conceptualized and planned this study, she went home to be with her Lord and Savior Jesus Christ before having the opportunity to see her plans come to fruition. We miss Jill greatly and dedicate this study to her.

\section{Acknowledgement}

We wish to thank the reviewers for their insightful and constructive comments from their initial review of this manuscript.

\section{References}

Bair, C. R. (1999). Doctoral student attrition and persistence: A meta-synthesis. (Doctoral dissertation, Loyola University, Chicago, 1999). Dissertation Abstracts International.

Berelson, B. (1960). Graduate education in the United States. The University of Michigan: McGraw Hill.

Bergen, G., \& Bergen, M. B. (1978). Quality of marriage of university students in relation to sources of financial support and demographic characteristics. The Family Coordinator, 27(3), 245-250.

Brailsford, I. (2010). Motives and aspirations for doctoral study: Career, personal, and inter-personal factors in the decision to embark on a history Ph.D. International Journal of Doctoral Studies, 5, 15-27. Retrieved from http://ijds.org/Volume5/IJDSv5p015-027Brailsford283.pdf

Bowen, W., \& Rudenstine, N. (1992). In pursuit of the Ph.D. Princeton, NJ: Princeton University Press.

Castro, V., Garcia, E. E., Cavazos, J., \& Castro, A. Y. (2011). The road to doctoral success and beyond. The International Journal of Doctoral Studies, 6, 51-77. Retrieved from http://ijds.org/Volume6/IJDSv6p051-077Castro310.pdf

Cao, W. (2001). How male and female doctoral students experience their doctoral programs similarly and differently. Paper presented at the annual meeting of the American Educational Research Association, Seattle, WA.

Cefai, C. (2004). Pupil resilience in the classroom: A teacher's framework. Emotional and Behavioral Difficulties, 9(3), 149-170.

Clauss-Ehlers, C. S. (2008) Sociocultural factors, resilience, and coping: Support for a culturally sensitive measure of resilience. Journal of Applied Developmental Psychology, 29, 197-212.

Council of Graduate Schools. (2008). Ph.D. completion and attrition: Analysis of baseline program data from the Ph.D. completion project. Washington, DC.

Creswell, J. W. (2007). Qualitative inquiry \& research design: Choosing among five approaches (2nd ed.). Thousand Oaks, California: Sage Publications.

de Valero, F. Y. (2001). Departmental factors affecting time-to-degree and completion rates of doctoral students at one land-grant research institution. The Journal of Higher Education, 72(3), 341-367.

Dorn, S. M., Papalewis, R., \& Brown, R. (1996). Educators earning their doctorates: Doctoral student perceptions regarding cohesiveness and persistence. Education, 116(2), 305-314.

Earl-Novell, S. (2006). Determining the extent to which program structure features and integration mechanisms facilitate or impede doctoral student persistence in mathematics. International Journal of Doctoral Studies, 1, 45-57. Retrieved from http://www.ijds.org/Volume1/IJDSv1p045-057Earl16.pdf

Gardner, S. K. (2009). Student and faculty attributions of attrition in high and low-completing doctoral programs in the United States. Higher Education, 58, 97-112.

Garmezy, N. (1971). Vulnerability research and the issue of primary prevention. American Journal of Orthopsychiatry, 41(1), 101-116. 
Giles, F. (1983). The effects of doctoral study on marriage and family: An ethnographic study. Paper presented at the annual meeting of the American College Personnel Association. Houston, TX.

Golde, C. M. (2000). Should I stay or should I go? Student descriptions of the doctoral attrition process. The Review of Higher Education 23(2), 199-227.

Golde, C. M. (2005). The role of the department and discipline in doctoral student attrition: Lessons from four departments. The Journal of Higher Education, 76(6), 669-700.

Golde, C. M., \& Dore, T. M. (2001). At cross purposes: What the experiences of doctoral students reveal about doctoral education. Philadelphia, Pew Charitable Trusts.

Grover, V. (2007). Successfully navigating the stages of doctoral study. International Journal of Doctoral Studies, 2, 9-21. Retrieved from http://www.ijds.org/Volume2/IJDSv2p009-021Grover21.pdf

Grotberg, E. H. (2003). Resilience for today: Gaining strength from adversity. Westport, CT: Praeger Publishers.

Herzig, A. H. (2002). Where have all the doctoral students gone? Participation of doctoral students in authentic mathematical activity as a necessary condition for persistence toward the Ph.D. Educational Studies in Mathematics, 50, 177-212.

Hoskins, C. M., \& Goldberg, A. D. (2005). Doctoral student persistence in counselor education programs: Student-program match. Counselor Education and Supervision, 44(3), 175-188.

Hyun, J. H. (2009). An exploration of the coping strategies in female counseling doctoral students' marriages. Dissertations. Paper 37. Retrieved from http://digitalarchive.gsu.edu/cps_diss/37

Itasca, Y. (2001). Contributions of leisure to coping with daily hassles in university students' lives. Canadian Journal of Behavioral Science, 33, 128-142.

Ivankova, N. V., \& Stick, S. L. (2007). Students' persistence in a distributed doctoral program in educational leadership in higher education: A mixed methods study. Research in Higher Education, 48(1), 93-135. doi:10.1007/s11162-006-9025-4

Jimenez, C. (2011). Predictors of well-being and depression among Latino college students. Ph.D. dissertation, University of Houston, United States - Texas. Retrieved from Dissertations \& Theses: Full Text. (Publication No. AAT 3485056).

Knowles, M. S. (1980). The modern practice of adult education. New York: Adult Education.

Levine, J. (2007). Comparative effects of alternative reading instructional approaches on the short- and long-term word recognition and attitude test scores of first-grade students. Doctoral dissertation, St. John's University.

Lincoln, Y. S., \& Guba, E. G. (1985). Naturalistic inquiry. Beverly Hills, CA: Sage.

Lott, J., Gardner, S. K., \& Powers, D. A. (2009). Doctoral student attrition in the STEM fields: An exploration of event history analysis. The Journal of College Student Retention, 11, 247-266.

Lovitts, B. E. (2001). Leaving the ivory tower: The causes and consequences of departure from doctoral study. Lanham, UK: Rowman \& Littlefield Publishers.

Lovitts, B. E. (2005). Being a good course-taker is not enough: A theoretical perspective on the transition to independent research. Studies in Higher Education, 30(2), 137-154.

Luthar, S. S., Cicchetti, D., \& Becker, B. (2000). The construct of resilience: A critical evaluation and guidelines for future work. Child Development, 71(3), 543-562.

Maher, M. A., Ford, M. E., \& Thompson, C. M. (2004). Degree progress of women doctoral students: Factors that constrain, facilitate, and differentiate. The Review of Higher Education, 27(3), 385-408.

McAlpine, L., \& Norton, J. (2006). Reframing our approach to doctoral programs: An integrative framework for action and research. Higher Education Research \& Development, 25(1), 3-17. 
Middleton, S. (2001). Making room: The place of academic study. Paper presented at the annual meeting of the American Educational Research Association, Seattle, WA.

Moustakas, C. (1994). Phenomenological research methods. Thousand Oaks, CA: Sage.

National Science Foundation (NSF). (2009). Doctorate recipients from U.S. universities: Summary report 2007-08. Chicago: National Opinion Research Center.

Nelson, N. G., Dell’Oliver, C., Koch, C., \& Buckler, R. (2001). Stress, coping, and success among graduate students in clinical psychology. Psychological Report, 88, 759-767.

Nettles, M. T., \& Millett, C. M. (2006). Three magic letters: Getting to Ph.D. Baltimore: John Hopkins University Press.

Norris, C., \& Barnett, B. (1994). Cultivating a new leadership paradigm: From cohorts to communities. Paper presented at the Annual Meeting of the University Council for Educational Administration, Philadelphia, PA. (ERIC Document Reproduction No. ED387877).

Norton, L. S., Thomas, S., Morgan, K., Tilley, A., \& Dickins, T. E. (1998). Full-time studying and longterm relationships: Make or break for mature students? British Journal of Guidance and Counseling, 26(1), 75-88.

Patton, M. Q. (1990) Qualitative evaluation and research methods ( $2^{\text {nd }}$ Ed.). Newbury Park, California: Sage Publications.

Pauley, R., Cunningham, M., \& Toth, P. (1999). Doctoral student attrition and retention: A study of a nontraditional Ed.D. program. Journal of College Student Retention, 1(3), 225-238.

Price, J. (2006). Does a spouse slow you down?: Marriage and graduate student outcomes. Unpublished manuscript.

Rodwell, J., \& Neumann, R. (2008). Predictors of timely doctoral completions by type of attendance: The utility of pragmatic approach. Journal of Higher Education Policy and Management, 301(1), 65-76.

Rovai, A. (2002). Development of an instrument to measure classroom community. Internet and Higher Education, 5(3), 197-211.

Smallwood, S. (2004, January 16). Doctor dropout. The Chronicle of Higher Education. Retrieved from http://chronicle.com/prm/weekly/v50/i19/19a01001.htm

Smith, R.L., Maroney, K., Nelson, K. W., Abel, A. L., \& Abel, H. S. (2006). Doctoral programs: Changing high rates of attrition. Humanistic Counseling, Education, and Development, 45, 17-31.

Stiles, J. E. M. (2003). The hazard of success: A longitudinal study of time-to-degree among doctoral students using discrete-time survival analysis. Ph.D. dissertation, Harvard University, United States Massachusetts, Retrieved from Dissertations \& Theses: A \& I database. (Publication No. AAT 3100170).

Strayhorn, T. L. (2005). More than money matters: An integrated model of graduate student persistence. Unpublished doctoral dissertation, Virginia Tech, Virginia.

Tenenbaum, H. R., Crosby, F. J., \& Gliner, M. D. (2001). Mentoring relationships in graduate school. Journal of Vocational Behavior, 59(3), 326-341. doi:10.1006/jvbe.2001.1804

Terrell, S.R. (2002). The effect of learning style on doctoral course completion in a web-based learning environment. The Internet and Higher Education, 5(4), 345-352.

Terrell, S. R., Snyder, M. M., \& Dringus, L. P. (2009). The developmental, validation, and application of the doctoral student connectedness scale. The Internet and Higher Education, 12(2), 112-116.

Tinto, V. (1975). Dropout from higher education: A theoretical synthesis of recent research. Review of Educational Research, 45(1), 89-125.

Tinto, V. (1993). Leaving college: Rethinking the causes and cures of student attrition (2 ${ }^{\text {nd }}$ ed.). Chicago: The University of Chicago Press. 
Tinto, V. (1997). Classrooms as communities: Exploring the educational character of student persistence. Journal of Higher Education, 68(6), 82.

Tinto, V. (1998). Colleges as communities: Taking research on student persistence seriously. The Review of Higher Education, 21(2), 167-177.

Torres, J. B., \& Solberg, V. S. (2001). Role of self-efficacy, stress, social integration, and family support in Latino college student persistence and health. Journal of Vocational Behavior, 59, 53-63.

Wao, H. O. (2010). Time to the doctorate: Multilevel discrete-time hazard analysis. Educational Assessment, Evaluation and Accountability, 22(3), 227-247.

Wao, H. O., \& Onwuegbuzie, A. J. (2011). A mixed research investigation of factors related to time to the doctorate in education. International Journal of Doctoral Studies, 6, 115-134. Retrieved from http://ijds.org/Volume6/IJDSv6p115-134Wao320.pdf

Werner, E. E., Bierman, J. M., \& French, F. E. (1971). The children of Kauai: A longitudinal study from the prenatal period to age ten. Honolulu: University of Hawaii Press.

Wasburn-Moses, L. (2008). Satisfaction among current doctoral students in special education. Remedial and Special Education, 29(5), 259-268.

West, I. J., Gokalp, G., Edlyn, V., Fischer, L., \& Gupton, J. (2011). Exploring effective support practices for doctoral students' degree completion. College Student Journal, 45(2), 310-323.

Williams, R. E. (1977). The perception of the impact of a doctoral program upon the marriage relationships of doctoral students at the University of Northern Colorado (Doctoral dissertation, University of Northern Colorado, 1977). Dissertation Abstracts International, 38, 132.

\section{Biographies}

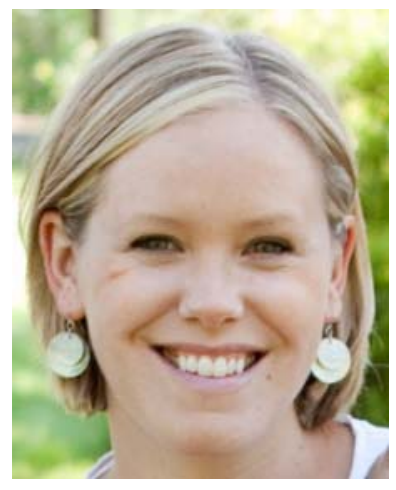

Lucinda Spaulding is an Assistant Professor and teaches education and research courses at the undergraduate, graduate, and doctoral level in Liberty University's School of Education. Dr. Spaulding has a Ph.D. in Special Education and Educational Psychology, a M.Ed. in Special Education, and a B.S. in Elementary Education. Dr. Spaulding was born and raised in Ottawa, Canada and has taught in general education, special education, and inclusion settings in Title 1 schools in New York and Virginia, and English as a second language in Japan. Her research interests include resilience in children and youth, specific learning disabilities and methods of best practice, the history of special education, and factors associated with doctoral attrition and persistence.

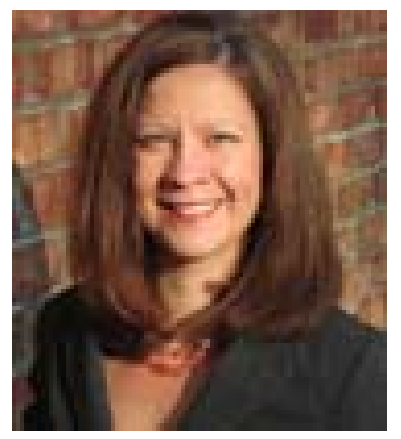

Amanda J. Rockinson-Szapkiw is an Assistant Professor and Chair of Doctoral Research for Liberty University's School of Education. She teaches doctoral research, educational technology, and school counseling courses. In her role of chair, she supports online and residential faculty and candidates through the dissertation process through the development and implementation of processes, materials, online and mobile resources, web-based trainings, and collaborative workspaces Dr. Rockinson- Szapkiw has an Ed.D. in Distance Education, a M.A. in Counseling, and a B.S. in Elementary Education. Dr. Rockinson-Szapkiw served as a counselor in the United States and overseas, specializing in childhood emotional, social, behavioral, and developmental problems for over five years before entering the world of Higher Education, and specializing in distance education course design. Her research has focused on community in distance education, counselor education leadership, and doctoral persistence. 